\title{
On the Habitus of the Court Interpreter
}

\author{
Yan Cao \\ Foreign Language School \\ East China University of Political Science and Law \\ Shanghai, China \\ Email: zoe_cao29@163.com
}

\begin{abstract}
Interpretation occurs in society, and therefore theories of sociology may offer us new insights into the role of the court interpreter. By drawing on the theory of practice by the French sociologist Pierre Bourdieu, this study sets out to explore the habitus of the court interpreter. It is found that both interpreting practice and interpreter training have important impact on court interpreter's habitus. And interpreter's habitus has a specific and lasting effect on his interpreting strategy.
\end{abstract}

Keywords-Court interpreter; Role; Habitus; Visibility

\section{INTRODUCTION}

Court interpreting, also known as forensic interpreting, legal interpreting or legal interpreting. From many research literatures, "court interpreting" is the most frequently used term. In a narrow sense, "court interpreting" refers only to interpreting in a court setting. In a broad sense, interpreting services provided by the court in the trial of the case, as well as interpreting services in other relevant judicial places outside the court, such as the police office, the refuge (refugee), the immigration office, the detention house or the law firm, can also be classified as the category of "court interpreting" [1]. A court interpreter needs to complete a series of tasks, including assisting the judicial authorities to interrogate witnesses and suspects, to help lawyers communicate with the parties, to interpret the proceedings to the accused or the litigants, and to interpret the testimony of the witnesses.

Court interpreting is a necessary means to ensure judicial justice [2-6]. The correct understanding of the role of the court interpreters is the prerequisite for the successful interpretermediated communication. Although many scholars have made important achievements in the study of the role of interpreters from the perspective of translation, pointing out interpreters are participants of communication, but these achievements have not yet been widely recognized by the public. The role of the court interpreter is still a "translation machine" or a "conduit", and the codes of conduct in court interpreting still require the interpreter to remain absolutely "neutral" and "invisible". This is not good for both interpreters and participants in communication. Nor is it conducive to ensuring judicial justice.

Drawing on the theory of practice, one of the most influential theories in sociology, this paper sets out to analyze the role of the court interpreter by focusing on the habitus of the interpreter.

\section{THE CONCEPT AND CHARACTERISTICS OF HABITUS}

\section{A. The Concept of Habitus}

Habitus is one of Bourdieu's most influential yet ambiguous concepts, and is considered one of his greatest contributions to the field of sociology. Bourdieu defines habitus as a "system of acquired dispositions functioning on the practical level as categories of perception and assessment or as classificatory principles as well as being the organizing principles of action" [7]. It is the way people view the world and act in society based on the events they experience and their encounters in society.

Habitus is "the way society becomes deposited in persons in the form of lasting dispositions, or trained capacities and structured propensities to think, feel and act in determinant ways, which then guide them" [8].

Habitus is created through a social, rather than individual process leading to patterns that are enduring and transferrable from one context to another, but that also shift in relation to specific contexts and over time.

Habitus is neither a result of free will, nor determined by structures, but created by a kind of interplay between the two over time [9].

\section{B. The Characteristics of Habitus}

According to Bourdieu, 'habitus' shapes the way we understand, interpret, and act in everyday life. Habitus is not a set of consciously held beliefs or values. Rather, it operates below the level of consciousness as a kind of second nature. Habitus enables the individual to navigate their way in society and guides them in their choices. It has the following main characteristics.

Habitus is durable because, like rock formations, it is formed over a long period, beginning with childhood socialization.

Habitus is transposable, i.e. transferable (rather like transferable skills), operating across a variety of settings, e.g. economic, political, social, artistic, religious etc.

Habitus is class-specific, which means it is formed within the social and cultural environment particular to a social class. Though no two personal biographies are identical, members of the same class experience much more in common, than they do 
with members of other classes. Hence, they tend to share the same or similar habitus.

Habitus is both structured and structuring. On the one hand, it is the product of our position in the social structure. On the other hand, it shapes our thoughts and actions ('practice'), which also maintain (reproduce) the social structure. Habitus is therefore, "the product of structure, producer of practice, and the reproducer of structure" [8].

\section{THE FORMATION OF THE INTERPRETER'S HABITUS}

As with the habitus of other actors, the habitus of the interpreter is a persistent disposition system that has been deposited in a series of historical practices and internalized as mental structures in the structural field. But different from the habitus of other actors, an interpreter's habitus is the result of internalization of a series of historical practice in the structured field. The habitus is an important part of an interpreter's interpreting style and model, which is closely linked with the interpreter's language use. The habitus has become a combination of an interpreter's mental state, attitude, taste, language style and action mode.

\section{A. Interpreting Practice and the Interpreter's Habitus}

The practical experience of the interpreter in the native language environment and the practical experience in the foreign language environment constitute the unique double cultural habitus of the interpreter, which forms the unique logic of the interpreter's language practice, and guides the interpreter to complete the interpretation task. Double cultural habitus makes interpreters to ally with those with the same mother tongue and cultural background, or to agree with the values and work goals of a certain party because they have cooperated or worked together. In any of these cases, the interpreter may be inclined to one party in the position or attitude consciously or unconsciously, and help the ally through language or non language means. As a result, it is difficult for the interpreter to be completely neutral [10].

\section{B. Interpreter Training and the Interpreter's Habitus}

Different from the common people, there is one more important factor in the formation of interpreters' habitus---the interpreter training. Interpreters' training experience constitutes one of the original experiences of interpreters. How does the interpreter acquire the skills of interpretation? Who is the trainer? What training materials are used? What kind of people does the interpreter contact in the course of the training? All these factors, together with other social and historical practice of the interpreter, are gradually internalized into the consciousness of the interpreter through a certain period of accumulation. Deeply embedded in the psychological structure, these form the interpreter's attitudes and views on the language and related culture, customs and the way of thinking of the interpreter.

\section{THE EFFECT OF HABITUS ON THE ROLE OF THE COURT INTERPRETER}

\section{A. The importance of court interpreter's habitus}

The habitus of the interpreter is an important part of the interpreter's style of interpretation and interpreting mode, and is closely related to the language usage psychology of the interpreter. It is not only an inseparable part of interpreter's behavior, but also an internal crystallization of the social environment and historical conditions of the interpreter. Habitus is deeply rooted in the temperament system of interpreters. From the point of view of practical operation, it is the generative ability and creative art that exists as a skill.

Habitus permeates both the internal and external of the interpreter, which guides the interpreter's interpretation in practice and demonstrates the style and temperament of the interpreter. It not only records the work experience and educational experience of the interpreter, but also achieves innovation in different circumstances. It has consistent stability and continuity, and changes at any time and place under restrictive conditions of different interpreters. It not only expresses the personality and endowment of the interpreter, but also permeates the class nature of the interpreter group. It can be accurately grasped in the way of empirical experience, and is also displayed by uncertain fuzzy features. As a result of the long-term internalization of the social structure, it is manifested by the disposition tendency of the interpreter, and is actively externalized to the present practice of interpretation, and the new social structure is continuously produced. It is not only accompanied by the subsistence mentality and life style of the interpreter anytime and anywhere, but also the "active in passive" and "passive in active", which combines historical experience and real time creation. Habitus is the unity of the objective conditions of society and the subjective creativity of the interpreter.

\section{B. Difference between the Role of Conference interpreters and Court Interpreters}

All parties in communication have certain social and economic status, from a certain nation or country, belonging to a certain gender. The interpreter is no exception. In many interpreting activities, interpreters often share similar social attributes with both parties. For example, at a certain international conference, the monolingual parties (representatives, speakers, etc.) may vary in nationality and sex, but have a similar social background and economic status, and have a common understanding of the topics discussed at the conference. The only difference between them is they speak different languages. Conference interpreters are often well educated, so they have similar social attributes to these representatives, such as education level. Under such circumstances, the influence of social factors on interpreters is not obvious. The interpreters remain relatively neutral and are relatively invisible in communicative activities. 
However, in court interpreting, judges, lawyers and defendants not only speak different languages, but also have different social status. In the environment of the court trial, the judges or lawyers have control over the communication and interaction and a good knowledge of the legal system, the legal system and the legal culture of the country, whereas the defendant is obviously in a weak position in communication and does not understand the local legal system, the legal system and the legal culture. When the distribution of power is asymmetric, the court interpreter may have more similarities with one party in communication rather than both parties [11]. It is therefore almost impossible for the interpreter to be completely neutral and invisible. He or she tends to be more inclined to one party or the other. In such a communicative activity, the interpreter seldom tends to be equally inclined to both parties at the same time, unless the two parties have similar social status.

For example, an interpreter, after working for the immigration office for several years, may begin to identify with the goal of the institution, or at least the current communication goal of the immigrant officers they collaborate with at the moment. Or, on the contrary, the interpreter may have a feeling of more identification with minority or immigrant groups because of the negative experience when serving the institution, such as being suppressed or reproached, or after long-term contact with the disadvantaged group. These to kinds of feelings do not interfere with the professional skills of the interpreter, but the negotiation of meaning and the entire power relationship network may be affected in a subtle way in these processes.

\section{CONCLUSION}

According to Bourdieu [12], no communicative activity occurs in a social vacuum, and no party in communication is invisible or unbiased, and they bring their own ideas, values, or prejudices into the communicative activities. Habitus ensures the effective presence of previous experiences, which are stored in each person in the form of perception, thinking and behavior patterns to ensure the consistency of the interpreter's practical activities. Therefore, it is unwise to assume that the interpreter is totally unaffected by these social factors. By observing the actual work of the interpreter, scholars find that the interpreter is interacting with the objects of interpreting service [13-17].

Bourdieu classifies habitus as the dispositions an individual acquires in response to structures such as their family, class and the education they receive, and other conditions they encounter [7]. Knowledge of the two languages and cultures, professional skills and norms acquired in interpretation training, and interpretation experience, these elements have formed the habitus of the interpreter after a long period of accumulation. The habitus of the interpreter directly affects his attitude towards interpreting, his perception of the interpreter's role and the interpreting strategies used in practice.
Court interpreters' habitus not only records the life experience and educational experience of the interpreters, but also implements innovation in different circumstances. The manipulation and dominance of habitus on interpreters are unconscious. This habitus is usually neither understood nor transferred by personal will. The reason why habitus has a specific and lasting effect is because it performs more effectively before the interpreter's consciousness and language operation, which is beyond the scope of will control.

\section{REFERENCES}

[1] Mikkelson, H. 1998. Towards a redefinition of the role of the court interpreter [J]. Interpreting: International Journal of Research and Practice in Interpreting, (1): 21-45.

[2] Berk-Seligson, S. 1990. The Bilingual Courtroom: Court Interpreters in the Judicial Process [M]. Chicago: University of Chicago Press.

[3] De Jongh, E. M. 1992. An Introduction to Court Interpreting: Theory \& Practice [M]. Lanham, Md.: University Press of America.

[4] Hale, S. 2002. How faithfully do court interpreters render the style of non-English speaking witnesses' testimonies? A data-based study of Spanish-English bilingual proceedings [J]. Discourse Studies, (1): 25-47.

[5] Morris, R. 1995. The moral dilemmas of court interpreting [J]. The Translator, (1): 25-46.

[6] Roberts, R.P. Community Interpreting Today and Tomorrow[A]. In S.E. Carr, R. Roberts, A. Dufour \& D. Steyn, (eds.). The Critical Link: Interpreters in the Community [C]. Amsterdam/Philadelphia: John Benjamins, 1997: 7-26.

[7] Bourdieu, P. 1990. The Logic of Practice [M]. Cambridge: Polity Press.

[8] Wacquant, L. 2005. Habitus. International Encyclopedia of Economic Sociology [C]. J. Becket and Z. Milan. London: Routledge.

[9] Bourdieu, P. 1986. The struggle for symbolic order[J] .Theory, Culture and Society, (3):35 -51.

[10] Ren Wen, Ian Mason. Power in dialogue Interpretation -- interpreting sociological interpretation [J]. Journal of Sichuan University (PHILOSOPHY AND SOCIAL SCIENCES), 2011 (06): 61-69.

[11] Angelelli, C. 2004. Revisiting the Interpreter's Role: A Study of Conference, Court, and Medical Interpreters in Canada, Mexico, and the United States [M]. Amsterdam. Philadelphia: John Benjamins Pub. Co.

[12] Bourdieu, P. 1989. Social Space and Symbolic Power [J]. Sociological Theory, (1): 14-25.

[13] Angelelli, C. 2001. Deconstructing the invisible interpreter: a critical study of the interpersonal role of the interpreter in a crosscultural/linguistic communicative event [D]. Unpublished Ph.D. thesis, Stanford University.

[14] Berk-Seligson, S. 2002. The Bilingual Courtroom: Court Interpreters in the Judicial Process: with a New Chapter [M]. Chicago: University of Chicago Press.

[15] Davidson, B. 2000. The Interpreter as Institutional Gatekeeper: The Social-linguistic Role of Interpreters in Spanish-English Medical Discourse [J]. Journal of Sociolinguistics, (3): 379-405.

[16] Kurz, I. Conference interpretation: Expectations of different user groups [A]. In Pochhacker, F. \& Shlesinger, M. (eds.). The Interpreting Studies Reader [C]. London/New York: Routledge, 2002: 313-324.

[17] Metzger, M. 1999. Sign Language Interpreting: Deconstucting the Myth of Neutrality [M]. Washington, DC: Gallaudet University Press. 